\title{
FOTOĞRAF YARDIMI İLE 3 BOYUTLU AĞAÇ MODELLENMESİNDE UYGUN PROGRAMIN ARAŞTIRILMASI
}

\author{
Ömer Faruk UZUN ${ }^{1}$, Atila GÜL² \\ ${ }^{1}$ Süleyman Demirel Üniversitesi, Fen Bilimleri Enstitüsü, Peyzaj Mimarlığı Anabilim Dalı(DR), Isparta, Türkiye \\ 2 Süleyman Demirel Üniversitesi, Mimarlık Fakültesi, Peyzaj Mimarlığı Bölümü, Isparta, Türkiye
}

\begin{tabular}{l} 
Anahtar Kelimeler \\
\hline Ağaç, \\
Üç boyutlu modelleme, \\
Tasarım, \\
Fotoğraf tabanlı, \\
Bilgisayar programları
\end{tabular}

\section{INVESTIGATION OF SUITABLE A PROGRAM THAT MAKES 3D TREE MODELLING FROM PHOTOGRAPHS}

Keywords
Tree,
Three dimensional modelling,
Design,
Image based,
Computer softwares

\begin{abstract}
In this study; photographs of trees, the main materials of planting design, were taken and it was studied if these 2D photographs could be converted into 3D models, by using various softwares such as Autodesk 123D Catch and Agisoft PhotoScan, with succession. For this purpose, photographs of Picea pungens Engelm. (Blue Spruce), Robinia pseudoacacia 'Umbraculifera' (False Acacia), Morus nigra 'Pendula' (Weeping Black Mulberry) and Chamaecyparis lawsoniana 'Ellwoodii' (Lawson's Cypress) were taken at site, using a camera, in different angles and using both softwares, their 3D models were created. The 3D models, which were created based upon the photographs, using Autodesk 123D Catch and Agisoft PhotoScan, were evaluated in 13 different criterations with assistance from specialists and their advantages and disadvantages were discussed to find the best 3D tree modelling software. As a conclusion, at 3D modelling of trees, the total point of Agisoft PhotoScas was higher than the total point of Autodesk 123D Catch and some of its properties was determined as more succesful.
\end{abstract}

\begin{tabular}{|c|c|}
\hline \\
\hline \multicolumn{2}{|c|}{$\begin{array}{l}\text { Uzun Ö. F., Gül A., (2017). Fotoğraf Yardımı il } \\
\text { Arastırılmasl, Journal of Enqineering Sciences and }\end{array}$} \\
\hline \multicolumn{2}{|c|}{ Yazar Kimliği / Author ID (ORCID Number) } \\
\hline $\begin{array}{l}\text { Ö. F. Uzun - 0000-0002-8541-4098 } \\
\text { A. Gül - 0000-0001-9517-5388 }\end{array}$ & \\
\hline & \\
\hline & \\
\hline & \\
\hline Iayım Tarihi / Publ & \\
\hline
\end{tabular}

\footnotetext{
* ilgili yazar: omerfarukuzun01@gmail.com, +90-246-211-3978
} 


\section{Giriş}

Bilgisayar tabanlı çalışmalarda bulunan farklı sektörler arasında, özellikle mimarlık ve tasarım sektörü önemli bir konuma sahiptir. Bilgisayar faktörünün tasarım sürecine ve sonucuna dâhil edilmesiyle birlikte karşımıza çıkan süreç kabaca; "Tasarım $\rightarrow$ Bilgisayar $\rightarrow$ Bilgisayar ortamında tasarım $\rightarrow$ Sonuç (Ürün)" şeklinde kabul edilmektedir (Akmehmet, 2006).

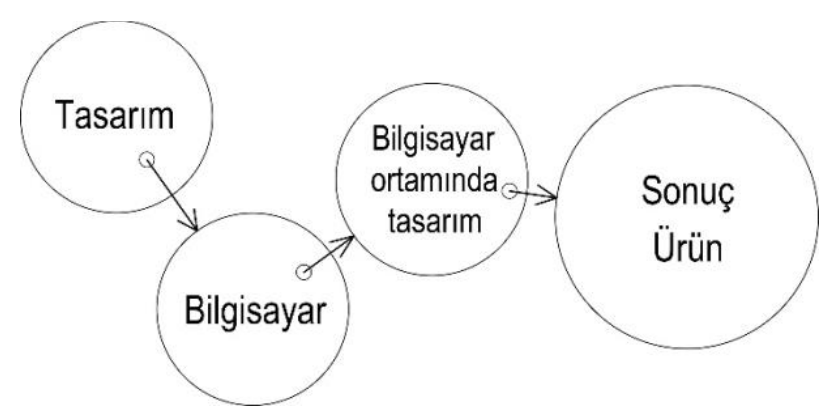

Şekil 1. Bilgisayar faktörü ile tasarım süreci

Üç boyutlu model çalışmaları, kentsel ve mimari tasarım uygulamalarda, restorasyon ve röleve çalışmalarında, imar-kadastro haritalarının hazırlanma aşamalarında ve internet ortamında online sanal mekan görünümler yaratmak açısından önemlilik arz etmektedir.

Peyzaj Mimarlığı disiplini kapsamında bitkisel tasarım projelerinde kullanılan ağaçlar, tasarımın ana materyalini oluşturmaktadır. Günümüzde giderek artan 3 boyutlu tasarım çalışmalarında özellikle 3 boyutlu ağaç görselleri giderek önem kazanmaya başlamıştır (Uzun, 2015).

Üç boyutlu bilgisayar modelleme programlarında yer alan bitkisel materyaller çoğu zaman modelleme çalışmaları kullanımında yetersiz kalmaktadır. Bu nedenle yardımcı olarak geliştirilen yama programlar ve çeşitli uygulama teknikleri ile bu eksiklikler giderilmeye çalışılmaktadır. Bunların yanı sıra fotoğraf üzerinde işlem yapmaya yardımcı olan programlar da bulunmaktadır. Bu programlar aracılığı ile kullanılmak istenilen bitki fotoğrafını çeşitli işlemlere tabi tutarak hazırlanan model üzerinde kullanımı mümkün olabilmektedir (Türker, 2013).

Bu çalışmada; Peyzaj Mimarlı̆̆ı disiplini kapsamında kullanılan ve özellikle tasarım çalışmalarının ana materyallerinden olan ağaçların, fotoğraf makinesi ile çekilen 2 boyutlu fotoğraflarının, Autodesk 123D Catch ve Agisoft PhotoScan adlı programlar yardımıyla, 3 boyutlu modeller haline getirilmesi ve kullanılabilme olanakları araştırılmıştır. Bununla birlikte fotoğraflar temel alınarak oluşturulan 3B ağaç modellerinin, diğer tasarım yazılımlarına entegrasyonu için en uygun modelleme yazllımlarının araştırılması ve bu yazılımların avantaj ve dezavantajlarının karşılaştırılarak en uygun yöntemin belirlenmesi öngörülmüştür. Böylece tasarımcı için ağaçların görsel olarak peyzaj tasarım sürecindeki modellenmesine ilişkin farklı bir yaklaşım ve öneriler ortaya konulmuştur.

\section{Bilimsel Yazın Taraması}

Literatür taraması sonucu fotoğraf yardımı ile 3B ağaç modellemesi konusunda ülkemizde yapılmış herhangi bir bilimsel çalışmaya rastlanılmamıștır.

Uluslararası alanda yapılmış olan çalışmalara baktığımızda; Shlyakhter vd. (2001), gerçekleştirdikleri çalışmada bilgisayar destekli 3 boyutlu ağaç modellemelerinin gerçekçi olmaması yönüyle ortaya çıkan sorunlardan bahsetmişler ve Lsystem metodu kullanılarak ağaçların gerçeğe uygun ve sağlıklı bir şekilde modellenmesine yönelik yeni bir yaklaşım ortaya koymuşlardır. Bir başka çalışma ortaya koyan Phattaralerphong ve Sinoquet (2005), yapmış olduğu çalışmada; 8 yönden (Kuzey, Kuzeydoğu, Güney, Güneydoğu, Batı, Doğu, Güneybatı, Güneydoğu) çekilen fotoğraflar ile oluşturulan veri setleri temel alınarak ağaç örtü hacmi modeli oluşturma metodu geliştirilmiştir.

Sen ve Day (2005) ise, ortaya koydukları çalışmada, doğanın en önemli unsurlarından biri olan ağaçlar, bazı teknikler kullanılarak modellenmiştir. Mevcut yöntemlerin bazıları ortaya çıkış sırasına göre tanımlanmıştır. Ağaçların, biyolojik ve geometrik yapıları göz önüne alınarak önce gövde ve dallanmaları ardından ise yaprakları modellenerek, ağaçların gerçeğine en yakın bir şekilde modellenmesi gerçekleștirilmiştir. Lu (2006), yapmış olduğu doktora tez çalışmasında; ağaç modelleme metotlarından biri olan Lignum metodu (L-System) kullanılarak ağaç gelişimi modellenmiş ve anlatırken, Dai vd. (2010), gerçekleștirdikleri çalışmada, ağaçların fotoğraf veri seti analizi ile 3 boyutlu ağaç modellemesini esas alan ve ağacın iskeletini, yapraklarını ve formunu en uygun bir şekilde oluşturmayı amaçlayan, farklı bir yaklaşımı ortaya koymuşlardır. Öte yandan lazer tarama yöntemi ile yapılan çalışmalarda bulunmaktadır. Örneğin; Graham ve Davies (2010), yaptıkları çalışmada, bir orman sahnesi simule etmek için lazer tarama (LIDAR) yöntemi ile oluşturulmuş 2 boyutlu ağaç görüntülerini temel alarak, Maya ve MATLAB yazılımlarını kullanarak, ağaçların 3 boyutlu noktasal bulut modelini geliştirmişlerdir.

Ülkemizde yapılan çalışmalara baktığımızda ise; Ağaçların fotoğraf yardımı ile değil de günümüzde kullanılan 3 boyutlu modelleme yöntemlerinden olan poly ve mesh modelleme yöntemleri kullanılarak yapıldığını görülmektedir. Örneğin; Türker (2013), yapmış olduğu yüksek lisans tez çalışmasında, Peyzaj Mimarlığı disiplini içinde ağaçlarının üç boyutlu olarak modellenmesi ve entegrasyonu için programların araştırılması (Maya, Blender, 3D Max, vb) ve bu programların avantaj ve dezavantajları karşılaştırılarak en uygun programın belirlenmesi 
amaçlamıştır. Bu amaçla Maya, Blender, 3D Max programları kullanılarak 3 boyutlu ağaç modeli geliştirilmiş ve uzmanlarla yapılan değerlendirme sonucu ideal ağaç modeli belirlenmiştir. Programlar arasında, kullanım kolaylığı, arayüz, modelleme, tekstür ve materyal, render kalitesi ve diğer programlarla çalışma uyumu kriterleri karşılaştırılmıştır.

İncelenen bu çalışmalara göre; ülkemizde Peyzaj Mimarlığında kullanılan ana materyallerden olan bitkilerin fotoğrafları kullanılarak olușturulan 3 boyutlu ağaç modellerine ilişkin yapılmış hiçbir çalışma bulunmamaktadır. Bu bağlamda ülkemizde bir ilk teşkil etmekte olup bundan sonra ilgililer için fotoğraf yardımı ile bir ağacın nasıl modellenebileceği konusunda bilimsel bir altlık oluşturacak bir çalışma özelliğindedir. Özellikle proje alan çalışmalarında, mevcut ağaçların ve çalışma alanının 3 boyutlu rölevesinin yapılmasında, alan sörveyinin olușturulmasında ve tasarım süreci esnasında; fotoğraf makinesi ile çekilen fotoğraflar kullanılarak hem proje alanının hem de alanda bulunan mevcut bitkisel materyallerin 3 boyutlu modellerin oluşturulması tasarımcı ve kullanıcıya pratik bir çözüm ve kolaylık sağlayacaktır.

\section{Materyal ve Yöntem}

\subsection{Materyal}

$\mathrm{Bu}$ çalışmanın teknik donanım ve materyalini, Schneider-KREUZNACH Lens'e ( $\mathrm{f}=4,0 \sim 72 \mathrm{~mm}$ ) ve 14,2 Megapiksel görüntü algılayıcısına sahip Samsung WB150F dijital fotoğraf makinası, Autodesk 123D Catch ve Agisoft PhotoScan bilgisayar yazılımları ve Intel Core i7-2670QM $(2.20 \mathrm{GHz}-3.10 \mathrm{GHz} 6 \mathrm{MB}$ Cache Bellek) işlemci, 8 GB (DDR3 1333 MHz.) ram kapasitesine sahip bir dizüstü bilgisayar oluşturmaktadır. Modellemede kullanılan ağaçlar ise özellikle Peyzaj Mimarlığı bitkisel tasarım uygulamalarında sıkça kullanılan ve piramit, yuvarlak, sarkık ve sütun formları gibi farklı görünümlere sahip olan, (Picea pungens Engelm. (Mavi Ladin), Robinia pseudoacacia 'Umbraculifera' (Top Akasya), Morus nigra 'Pendula' (Sarkık Dut) ve Chamaecyparis lawsoniana 'Ellwoodii' (Elvudi)) ağaçlardan modellenmek üzere seçilmiştir.

\subsection{Yöntem}

Bu çalışmada, konu ile ilgili olabileceği düșünülen yerli ve yabancı tüm veriler hakkında, yoğun bir literatür ve internet taraması yapılmıştır. Bu konuda özellikle yabancı kaynaklardan yararlanılmış ve çevirisi yapılarak çalışmanın yöntemi ortaya konulmuştur. Çalışmada, fotoğraf yardımı ile 3B modelleme amaçlı kullanılabilecek bilgisayar yazılımları araştırılmış ve bu yazılımların teknik özellikleri ortaya konulmuştur. Ardından yazılımların içerisinden, herhangi bir amatör kamera ile çekilen fotoğrafları kullanabilmesi, ağaçlar gibi büyük boyuttaki objelerin $3 \mathrm{~B}$ olarak modelleyebilmesi ve teknik açıdan asgari düzeyde donanım materyali ile çalışabilmesi gibi özelliklere sahip olan, 2 farklı bilgisayar programı (Autodesk 123D Catch ve Agisoft PhotoScan) seçilmiştir.

Fotoğraf çekimleri için öncelikle ağacın çevresinde $360^{\circ}$ dönülerek, etrafındaki nesnelerle birlikte, tekil olarak ve monopod çubuk kullanılarak, fotoğrafları çekilmiş ve böylece seçilen her bir ağaç türü için, tepe ve ağacın formunu ortaya koyacak şekilde ayrı ayrı fotoğraf veri setleri oluşturulmuştur (Tablo 1.). Her bir ağaç için ayrı olarak oluşturulan fotoğraf veri setleri, yaklașık 200-300 adet fotoğraf karesinden meydana gelmektedir. Ağaçların fotoğrafları güneşli veya çevreye nötr işık verecek kadar bulutlu havada, 10.00 ila 15.00 saatleri arasında çekilmiştir.

Tablo 1. Seçilen ağaçların fotoğraf veri setleri

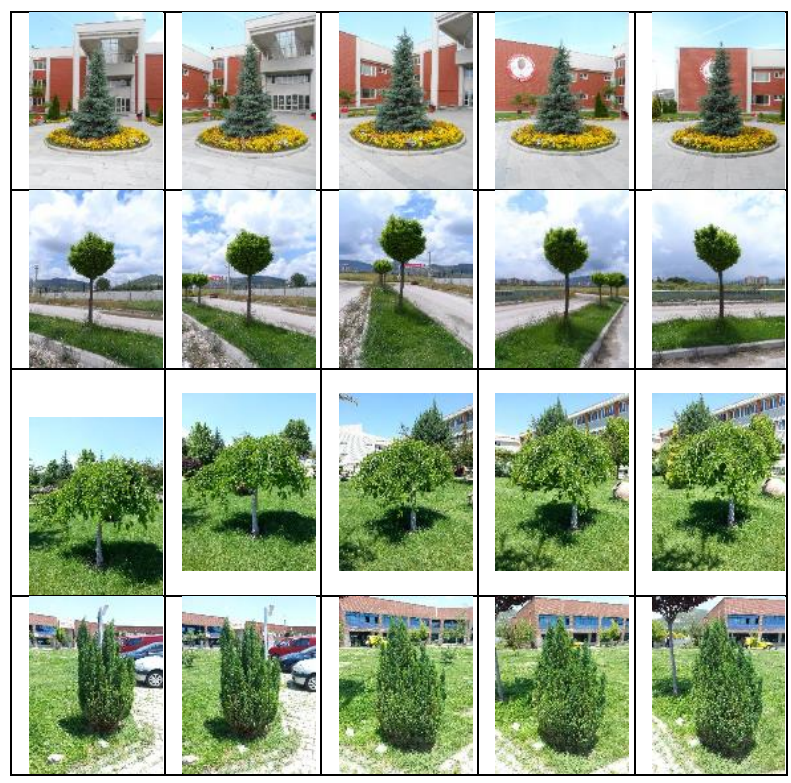

Her bir ağacın fotoğraf çekimi değișik açlardan yapılmıştır ve çekim açıları Şekil 2.'de verilmiştir.
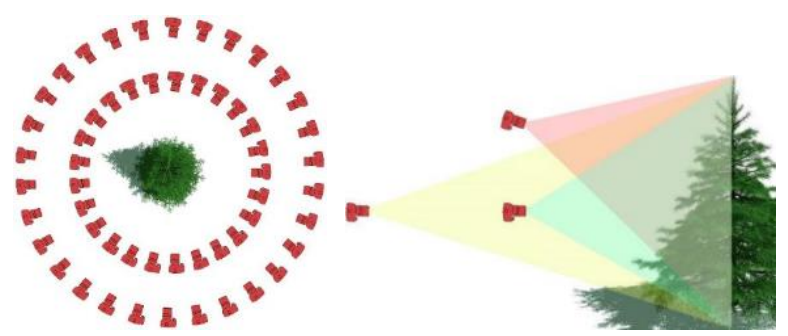

Şekil 2. Ağaç fotoğraflarının çekim açıları ve pozisyonları

Söz konusu ağaç türleri için oluşturulmuş olan fotoğraf veri setleri, Autodesk 123D Catch ve Agisoft PhotoScan programlarında kullanılarak, her türe ait görsel kalite ve teknik kriterleri açısından olmak üzere, 13 ayrı kriter bazında değerlendirilmiștir. Bu bağlamda görsel kalite ve teknik kriterler Tablo 2.'de verilmiştir. 
Tablo 2. Değerlendirme kriterleri ve Likert puanlama ölçeği

\begin{tabular}{|c|c|c|c|c|c|}
\hline \multirow[t]{2}{*}{ KRITTERLER } & 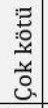 & 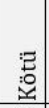 & $\stackrel{\pi}{2}$ &. & $\frac{\Sigma}{3}$ \\
\hline & 1 & 3 & 5 & 7 & 9 \\
\hline \multicolumn{6}{|l|}{ Görsel Kalite Kriterleri } \\
\hline \multicolumn{6}{|l|}{ Beyaz dengesi } \\
\hline \multicolumn{6}{|l|}{ Pozlama değerleri } \\
\hline \multicolumn{6}{|l|}{ Parlaklık ve kontrast aralık değeri } \\
\hline \multicolumn{6}{|l|}{ Fotoğraf çözünürlüğü } \\
\hline \multicolumn{6}{|l|}{ Işık ve gölge dengesi } \\
\hline \multicolumn{6}{|l|}{ Optik bozulma } \\
\hline \multicolumn{6}{|l|}{ Netlik } \\
\hline \multicolumn{6}{|l|}{ Alan derinliği } \\
\hline \multicolumn{6}{|l|}{ ISO hassasiyeti } \\
\hline \multicolumn{6}{|l|}{ Teknik Kriterler } \\
\hline \multicolumn{6}{|l|}{ Arayüz kolaylığı } \\
\hline \multicolumn{6}{|l|}{ Kullanım kolaylığı } \\
\hline \multicolumn{6}{|l|}{ Modelleme esnekliği } \\
\hline \multicolumn{6}{|l|}{ Diğer programlar ile çalıșma uyumu } \\
\hline $\begin{array}{l}\text { Olușturduğu 3B Modellerin gerçeğe yakınlık } \\
\text { düzeyi }\end{array}$ & & & & & \\
\hline
\end{tabular}

Analiz ve değerlendirmede temel alınan bu kriterler, üretilen 3B modellerin görsel kalite düzeyinin ortaya konması ve fotoğraf yardımı ile $3 \mathrm{~B}$ modelleme yapılabilecek programların teknik açıdan avantaj ve dezavantajlarının belirlenmesi için kullanılmıştır. Farklı programlar kullanılarak fotoğraflar yardımı ile elde edilen 3B ağaç modelleri, Peyzaj Mimarı (5 kişi), Mimar (3 kişi), Fotoğrafçı (5 kişi) ve Grafikerlerden (2 kişi) oluşan ilgili uzmanlar (Toplam 15 uzman) tarafindan yorumlanmak suretiyle puanlamalar yapılmış ve uzmanların bu konudaki görüşleri alınmıștır. Uzman anketi değerlendirme formları eposta ile uzmanlara gönderilmiş ve anketler bu şekilde yapılmıştır. Tamamen 3B modelleme, görselleştirme ve fotoğrafçılık alanlarında profillere sahip olan uzmanların, yorumları ve puanlamaları temel alınarak; üretilen 3B ağaç modelleri, görsel kalite açısından ve çalışmada kullanılan fotoğraf yardımı ile 3B modelleme yapan 2 program ise teknik açıdan değerlendirilip karşılaştırmalar yapılarak, avantaj ve dezavantajlar ortaya konulmuştur. Bu bağlamda ağaç modelleme için fotoğraf yardımı ile 3B modelleme konusunda kullanılabilecek en uygun program belirlenmiştir. Likert ölçeğinin temel amacı, bireylerin belirli tutumlar karşısındaki tavırlarını derecelendirmektir. Ayrıca bireylerin yalnızca bir tutum cümlesine karșı olup olmadıkları değil, tutumlarının yoğunluğunu da ölçmek istemesidir (Barlas vd. 1985). Bu yüzden puanlamada likert ölçeği kullanılmış olup; 1 puan çok kötü, 3 puan kötü, 5 puan orta, 7 puan iyi ve 9 puan çok iyi şeklindedir (Tablo 2.). Uzmanlar tarafından Likert ölçeğine göre yapılan puanlama sonucunda; kullanılan 2 programın aldığı puanların birbirine olan farkları, Tablo 3.'de verilen klyaslama ölçeği temel alınarak değerlendirilmiștir.
Buna göre, 0-45 puan arası düşük, 46-90 puan arası orta ve 91-135 puan arası yüksek avantajlı olarak değerlendirmeye tabi tutulmuştur (Tablo 3.).

Tablo 3. Kıyaslama ölçeği

\begin{tabular}{|c|l|}
\hline Puan Farkları & \multicolumn{1}{|c|}{ Ölçek } \\
\hline $0-44$ puan & Düşük Avantajlı \\
\hline $45-89$ puan & Orta Derecede Avantajlı \\
\hline $90-135$ puan & Yüksek Derecede Avantajlı \\
\hline
\end{tabular}

\section{Araştırma Bulguları}

\subsection{Fotoğraf Yardımı ile 3B Ağaç Modelleme için Kullanılan Programlar ve Uygulama Süreçleri}

Seçilen 4 ağaç türü için oluşturulan fotoğraf veri setleri, Autodesk 123D Catch ve Agisoft PhotoScan programlarında kullanılarak, ağaçların 3B modelleri elde edilmiştir.

\subsubsection{Autodesk 123D Catch programı ile ağaçların 3 boyutlu modellenmesi}

Autodesk 123D Catch programı çevrimiçi (online) çalışabilen bir programdır. $\mathrm{Bu}$ yüzden internet bağlantısı ile çalışmak gerekmektedir. Öncelikle Autodesk ID hesabı alınır ve bu hesap kullanılarak programa giriş yapılmaktadır. Ardından her bir ağaç için oluşturulan fotoğraf veri seti açlan iletişim penceresinde bulunur ve bütün fotoğraflar seçilerek aç kısmına tıklanır. Autodesk 123D Catch programı en az 20, en fazla ise 70 fotoğraf yüklenmesine izin vermektedir. Seçilen fotoğraflar eklendikten sonra 'Create Project' menüsü ortaya çlkmakta ve bu menüye tıklanmaktadır. Eğer daha fazla fotoğraf eklenmek istenirse 'Add More Photos' menüsüne tıklanıp ekleme yapılabilmektedir (Şekil 3.).

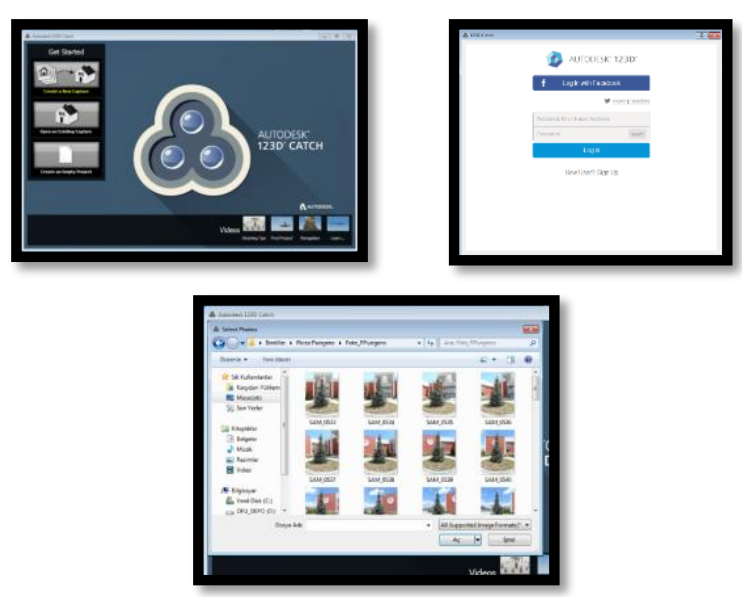

Şekil 3. Autodesk 123D Catch programına çevrimiçi fotoğraf yükleme așaması

'Create New Capture' menüsü tıklandıktan sonra gelen iletişim penceresine modelin ismi, tanımlayıcı etiketleri ve modelin türü (bina, bitki, araba vb.) gibi detaylar girilir ve istenilen 3 boyutlu model programa 
tanımlanır. İletişim penceresindeki kısımlar doldurulduktan sonra 'Create' tușu tıklanır. Ardından program birinci aşamada, seçilen fotoğraflar tanımlanır ve çevrimiçi Autodesk Cloud' a yüklenir, ikinci aşamada fotoğraflardan 3B model oluşturma işlemi yürütülür ve bu işlemi tamamlayınca üçüncü aşamada oluşturduğu 3B modeli Autodesk Cloud'tan indirilir (Şekil 4.).

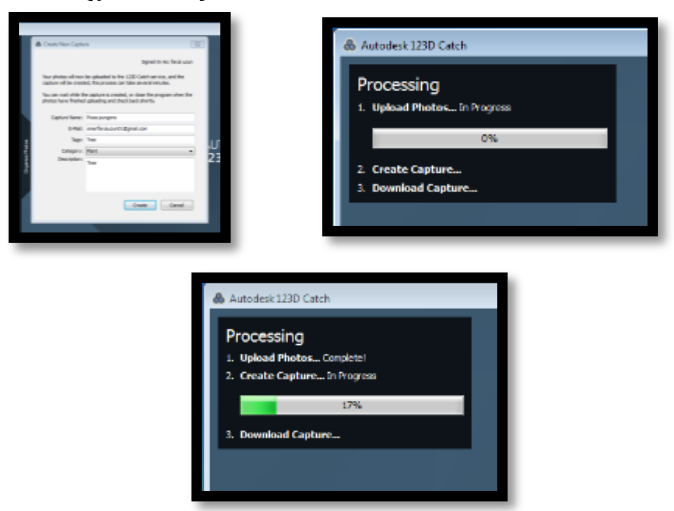

Şekil 4. Autodesk 123D Catch programına 3B ağaç modelini hakkında tanıtıcı bilgiler girilmesi ve çevrimiçi modelleme aşaması

Programda uygulanan bütün aşamalar sonucunda elde edilen Picea pungens Engelm. (Mavi Ladin) ağacının 3 boyutlu modeli Şekil 5.' deki gibidir.

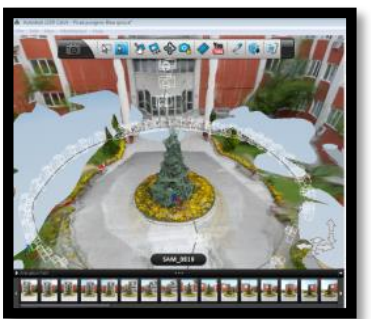

Şekil 5. Picea pungens Engelm. (Mavi Ladin) ağaç türünün Autodesk 123D Catch programında oluşturulmuş 3 boyutlu modeli

Çalışmada kullanılan diğer ağaç türleri de Autodesk 123D Catch programında yukarıda anlatılan işlemler uygulanarak modellenmiş olup, 3 boyutlu modelleri aşağıdaki gibidir (Şekil 6., Şekil 7., Şekil 8.).
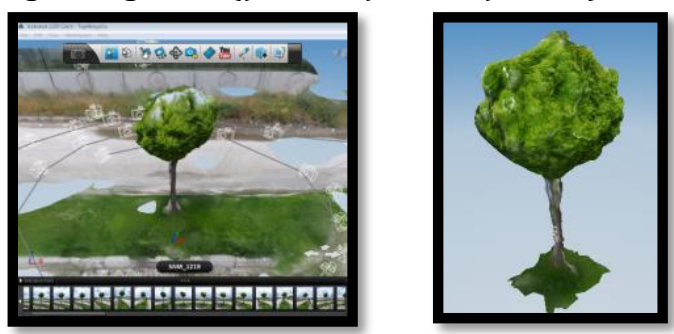

Şekil 6. Robinia pseudoacacia 'Umbraculifera' (Top Akasya) ağaç türünün Autodesk 123D Catch programında oluşturulmuş 3 boyutlu modeli
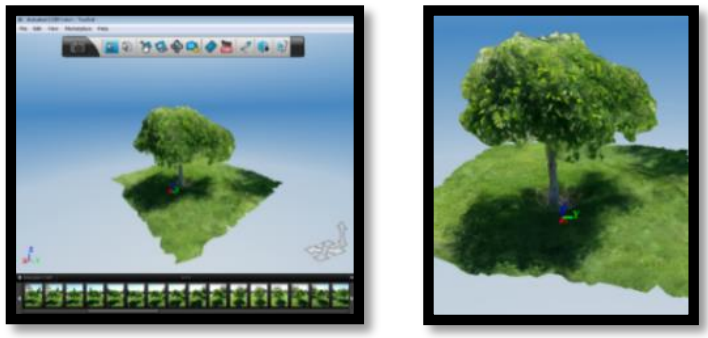

Şekil 7. Morus nigra 'Pendula' (Sarkık Dut) ağaç türünün Autodesk 123D Catch programında oluşturulmuş 3 boyutlu modeli
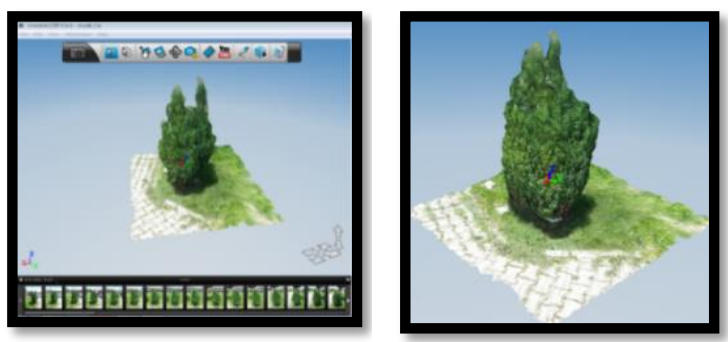

Şekil 8. Chamaecyparis lawsoniana 'Ellwoodii' (Elvudi) ağaç türünün Autodesk 123D Catch programında oluşturulmuş 3 boyutlu modeli

\subsubsection{Agisoft PhotoScan programı ile ağaçların 3 boyutlu modellenmesi}

Agisoft PhotoScan programı açlır ve Workflow > Add Folder yolu izlenerek modellenecek olan ağacının fotoğraf veri setinin bulunduğu klasör programa eklenir (Şekil 9.).
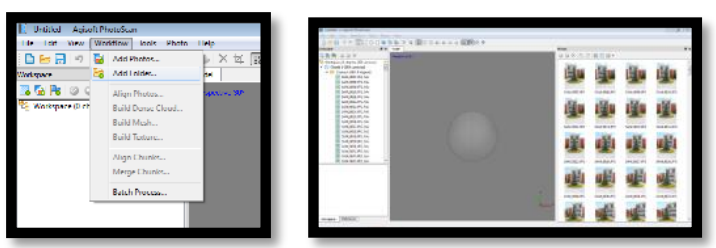

Şekil 9. Agisoft PhotoScan programına fotoğraf ekleme aşaması

Eklenen fotoğrafların programın algılayabilmesi için öncelikle hizalama işlemi (Align Photos) gerçekleştirilir. Bunun için Workflow > Align Photos yolu izlenir ve sonrasında gelen menüde 'Accuracy' (doğruluk) ayarı seçilerek 'Pair preselection' ayarı devre dışı bırakılır. Fotoğrafların hizalanması (Align Photos) işlemi ile program, çekilen fotoğrafların modellenecek nesneye olan uzaklıkları ve fotoğraf makinesinin çekim yaptığı konum hesaplanarak altlık olacak olan Tie Points'i (Bağ Noktaları Kümesi) oluşturulur (Şekil 10.). 

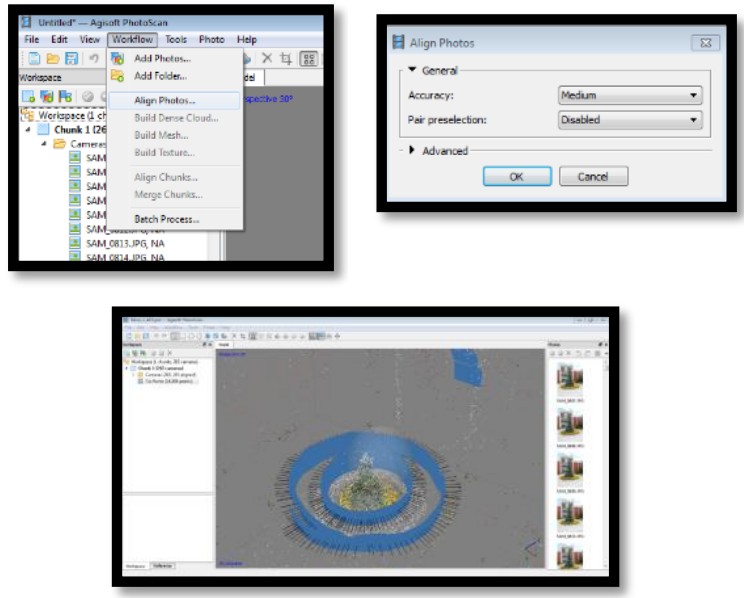

Şekil 10. Agisoft PhotoScan programı fotoğraf hizalama menüsü ve aşamaları

Ardından 3B olarak modellenecek olan ağacın noktasal bulutu oluşturulur. Bu yüzden Workflow > Build Dense Cloud yolu izlenir ve sonrasinda gelen menüde Quality ayarı (kalite) belirlenir. Nokta bulutu olușturma (Build Dense Cloud) ișlemi sonucunda modelleme aşamasında detaylar ortaya çıkarılır (Şekil 11.).
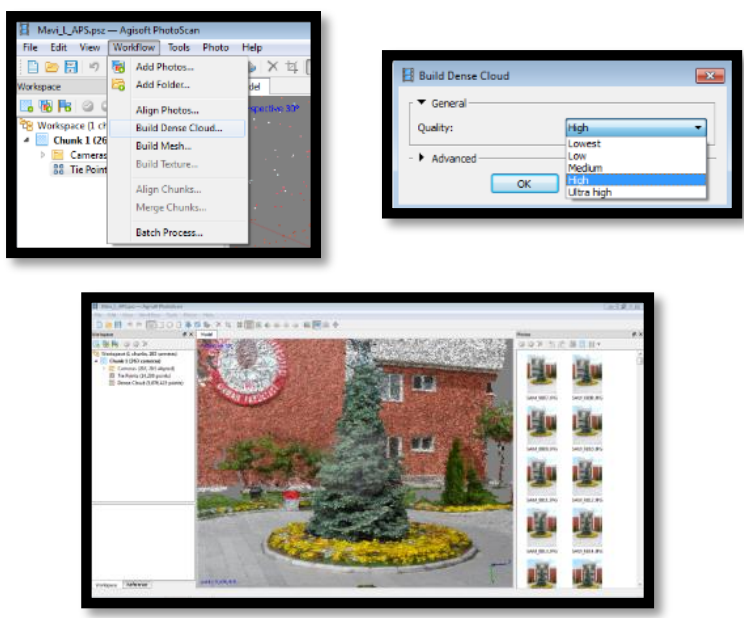

Şekil 11. Agisoft PhotoScan programı nokta bulutu oluşturma menüsü ve aşamaları

Ağaçların nokta bulutu oluşturulduktan sonra, bu noktalar birleștirilir ve $3 \mathrm{~B}$ poligon yüzeyler oluşturulur. Bu sebeple Workflow > Build Mesh yolu izlenir işlem sonucunda ise ağacın 3B poligon yüzeyleri oluşturulur (Şekil 12.).
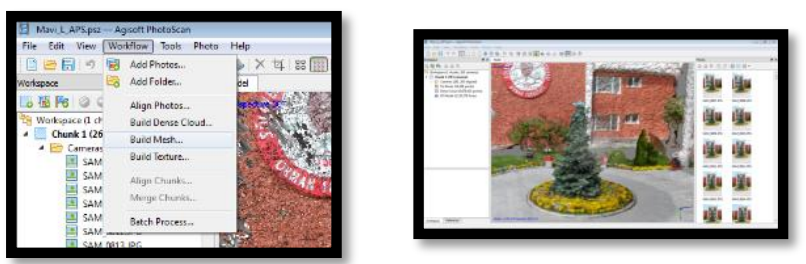

Şekil 12. Agisoft PhotoScan programı 3 boyutlu poligon yüzey olușturma menüsü ve așamaları
Bundan sonraki işlemde, oluşturulan 3B poligon yüzeyler üzerine ağacın fotoğrafları(tekstür) kaplanır. Bu yüzden Workflow > Build Texture yolu izlenir ve ilgili menüde Mapping Mode kısmı 'Generic' ve Bending Mode kısmı da 'Mosaic' olarak işaretlenir (Şekil 13.).
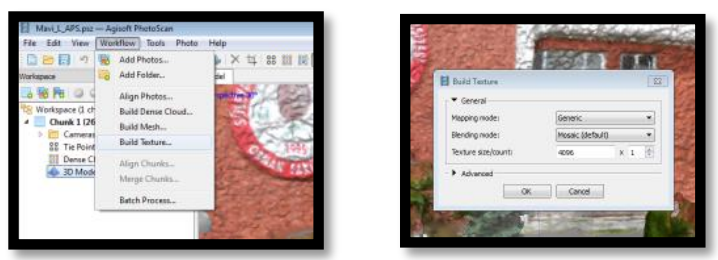

Şekil 13. Agisoft PhotoScan programı tekstür kaplama menüsü ve aşamaları

İşlem sonucunda fotoğrafların kaplanması tamamlanmış olup Picea pungens Engelm. (Mavi Ladin) ağacının 3 boyutlu modeli elde edilmiștir (Şekil 14. ).
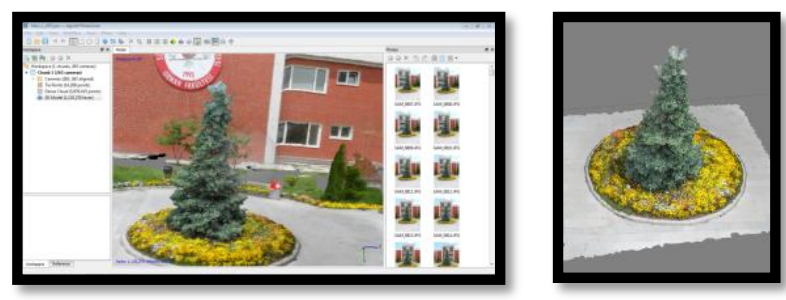

Şekil 14. Picea pungens Engelm. (Mavi Ladin) ağaç türünün Agisoft PhotoScan programinda oluşturulmuş 3 boyutlu modeli

Çalışmada kullanılan diğer ağaç türleri de Agisoft PhotoScan programında yukarıda anlatılan işlemler uygulanarak 3 boyutlu modelleri aşağıdaki gibidir (Şekil 15., Şekil 16., Şekil 17.).
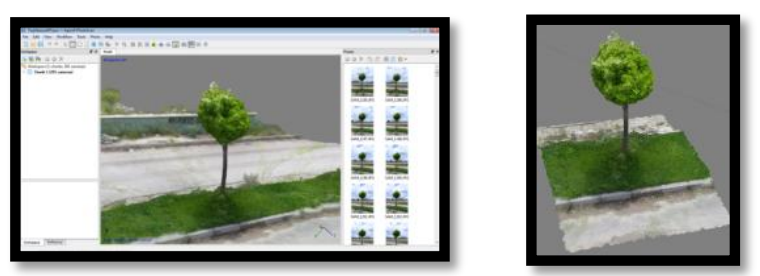

Şekil 15. Robinia pseudoacacia 'Umbraculifera' (Top Akasya) ağaç türünün Agisoft PhotoScan programında oluşturulmuş 3 boyutlu modeli
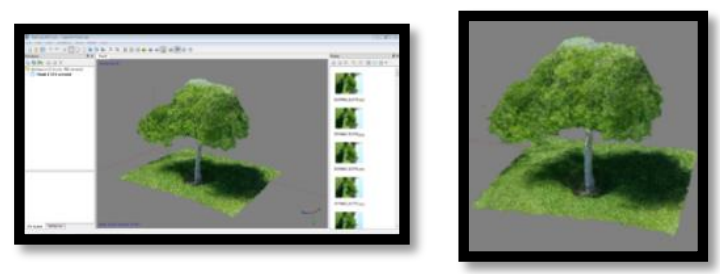

Şekil 16. Morus nigra 'Pendula' (Sarkık Dut) ağaç türünün Agisoft PhotoScan programında oluşturulmuş 3 boyutlu modeli 

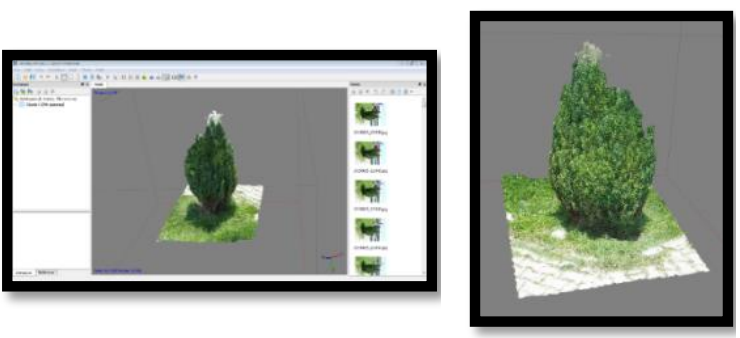

Şekil 17. Chamaecyparis lawsoniana 'Ellwoodii' (Elvudi) ağaç türünün Agisoft PhotoScan programında oluşturulmuş 3 boyutlu modeli

Her iki programda da modellenen 4 ağaç türünün 3B modelleme sonuçları aşağıdaki Şekil 18 a-b.'de verilmiştir.
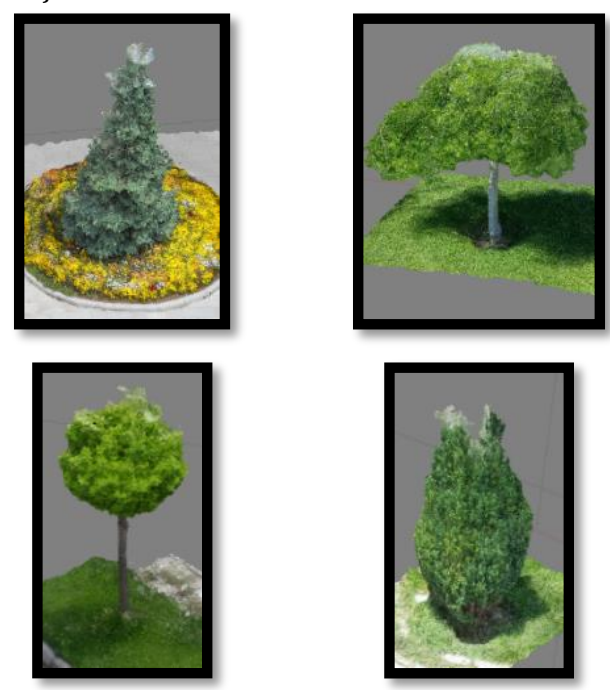

a) Agisoft PhotoScan yazılımı ile oluşturulan $3 B$ modeller
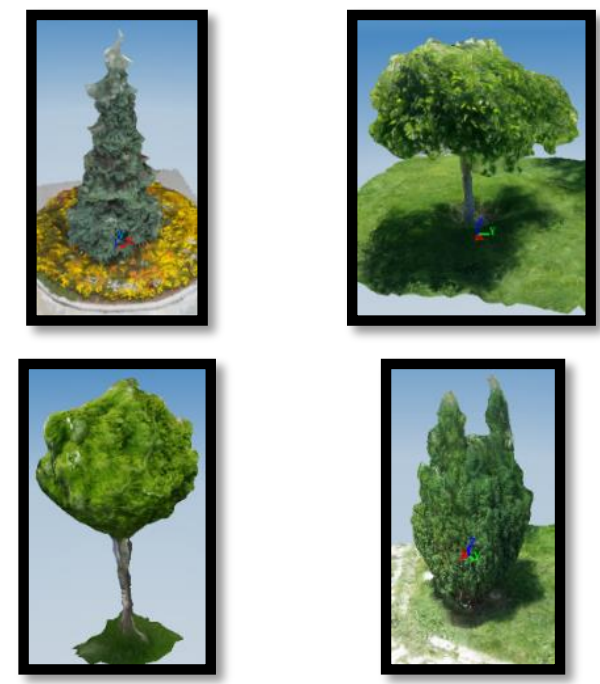

b)Autodesk 123D Catch yazılımı ile olușturulan 3B modeller

Şekil 18 a-b. Programlarda modellenen 4 ağaç türünün 3 boyutlu modelleme sonuçları

Autodesk 123D Catch ve Agisoft PhotoScan programları kullanılarak fotoğraflar yardımı ile elde edilen Picea pungens Engelm. (Mavi Ladin), Robinia pseudoacacia 'Umbraculifera' (Top Akasya), Morus nigra 'Pendula' (Sarkık Dut) ve Chamaecyparis lawsoniana 'Ellwoodii' (Elvudi) ağaç türlerinin 3B modelleri, Peyzaj Mimarı, Mimar, Fotoğrafçı ve Grafikerlerden oluşan 15 kişilik uzman grubu tarafından puanlanmıştır. Uzmanlar tarafından Likert ölçeğine göre yapılan puanlama sonucunda; kullanılan 2 programın avantaj ve dezavantajları kiyaslama ölçeğine göre değerlendirmeye tabi tutulmuştur.

Picea pungens Engelm. (Mavi Ladin) ağaç türü için Autodesk 123D Catch ve Agisoft PhotoScan programlarında oluşturulan 3B modellerin kıyaslanabilmesi için yapılan uzman anketi sonuçları değerlendirildiğinde, Agisoft PhotoScan programı toplamda en yüksek puanı alması ile daha avantajlı olduğu belirlenmiştir. Autodesk 123D Catch programı için kriterler değerlendirildiğinde, arayüz kolaylığı ve kullanım kolaylığı bakımından orta derecede avantaja sahip olduğu söz konusudur. Agisoft PhotoScan programına bakıldığında ise beyaz dengesi, pozlama değerleri, parlaklık ve kontrast aralık değeri, fotoğraf çözünürlüğü, ışık ve gölge dengesi, netlik, alan derinliği, ISO hassasiyeti, diğer programlar ile çalışma uyumu kriterleri açısından düşük derecede avantaj sağlarken, oluşturduğu 3B modellerin gerçeğe yakınlık düzeyi kriteri bakımından orta derecede avantajlı olduğu görülmektedir. Ayrıca, Agisoft Photoscan programı modelleme esnekliği kriterine göre yüksek derecede avantajlı olduğu görülmektedir. (Tablo 4.).

Tablo 4. Picea pungens Engelm. (Mavi Ladin) ağaç türü 3 boyutlu modeli uzman anketi puanlama çizelgesi

\begin{tabular}{|c|c|c|c|}
\hline KRITERLER & 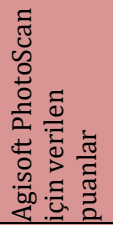 & 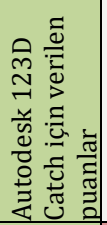 & 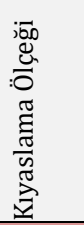 \\
\hline Beyaz dengesi & 93 & 63 & 30 \\
\hline Pozlama değerleri & 99 & 81 & 18 \\
\hline $\begin{array}{llll}\begin{array}{l}\text { Parlaklık } \\
\text { değeri }\end{array} & \text { ve } & \text { kontrast aralık } \\
\end{array}$ & 117 & 75 & 42 \\
\hline Fotoğraf çözünürlüğü & 105 & 69 & 36 \\
\hline Ișık ve gölge dengesi & 105 & 87 & 18 \\
\hline Optik bozulma & 93 & 93 & 0 \\
\hline Netlik & 93 & 57 & 36 \\
\hline Alan derinliği & 111 & 69 & 42 \\
\hline ISO hassasiyeti & 93 & 69 & 24 \\
\hline Arayüz kolaylığı & 63 & 135 & 72 \\
\hline Kullanım kolaylı̆ıı & 63 & 135 & 72 \\
\hline Modelleme esnekliği & 135 & 45 & 90 \\
\hline $\begin{array}{l}\text { Diğer programlar ile çalışma } \\
\text { uyumu }\end{array}$ & 135 & 105 & 30 \\
\hline $\begin{array}{l}\text { Oluşturduğu } 3 \mathrm{~B} \text { Modellerin } \\
\text { gerçeğe yakınlık düzeyi }\end{array}$ & 105 & 39 & 66 \\
\hline TOPLAM PUAN & 1410 & 1122 & 288 \\
\hline
\end{tabular}

Robinia pseudoacacia 'Umbraculifera' (Top Akasya) ağaç türü için Autodesk 123D Catch ve Agisoft PhotoScan programlarında oluşturulan 3B modellerin kıyaslanabilmesi için yapılan uzman anketi sonuçları değerlendirildiğinde, Agisoft PhotoScan programı 
toplamda en yüksek puanı alması ile Autodesk 123D Catch programına göre daha avantajlı olduğu belirlenmiştir. Autodesk 123D Catch programı puanlama çizelgesine göre değerlendirildiğinde, arayüz kolaylığı ve kullanım kolaylığı kriterleri bakımından orta derecede avantajlı bir program olduğu görülmektedir. Öte yandan Agisoft PhotoScan programının aldığı puanlara bakıldığında, pozlama değerleri, parlaklık ve kontrast aralık değeri, fotoğraf çözünürlüğü, optik bozulma, netlik, alan derinliği, ISO hassasiyeti ve diğer programlar ile çalışma uyumu kriterleri açısından düşük derecede avantajlı olduğu ortaya çıkmaktadır. Ayrıca Agisoft PhotoScan programı, ışık ve gölge dengesi kriteri açısından orta derecede, modelleme esnekliği ve oluşturduğu 3B modellerin gerçeğe yakınlık düzeyi kriterleri açısından yüksek derecede avantajlı olduğu belirlenmiştir (Tablo 5.).

Tablo 5. Robinia pseudoacacia 'Umbraculifera' (Top Akasya) ağaç türü 3 boyutlu modeli uzman anketi puanlama çizelgesi

\begin{tabular}{|c|c|c|c|}
\hline KRİTERLER & 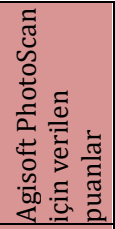 & 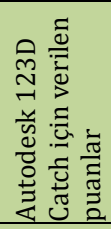 & 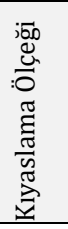 \\
\hline Beyaz dengesi & 87 & 87 & 0 \\
\hline Pozlama değerleri & 99 & 75 & 24 \\
\hline Parlaklık ve kontrast aralık değeri & 87 & 75 & 12 \\
\hline Fotoğraf çözünürlüğü & 93 & 69 & 24 \\
\hline Ișık ve gölge dengesi & 105 & 57 & 48 \\
\hline Optik bozulma & 99 & 69 & 30 \\
\hline Netlik & 81 & 39 & 42 \\
\hline Alan derinliği & 99 & 75 & 24 \\
\hline ISO hassasiyeti & 93 & 81 & 12 \\
\hline Arayüz kolaylığı & 63 & 135 & 72 \\
\hline Kullanım kolaylığı & 63 & 135 & 72 \\
\hline Modelleme esnekliği & 135 & 45 & 90 \\
\hline Diğer programlar ile çalıșma uyumu & 135 & 105 & 30 \\
\hline $\begin{array}{l}\text { Oluşturduğu 3B Modellerin gerçeğe } \\
\text { yakınlık düzeyi }\end{array}$ & 99 & 27 & 72 \\
\hline TOPLAM PUAN & 1338 & 1074 & 264 \\
\hline
\end{tabular}

Morus nigra 'Pendula' (Sarkık Dut) ağaç türü için Autodesk 123D Catch ve Agisoft PhotoScan programlarında oluşturulan 3B modellerin kıyaslanabilmesi için yapılan uzman anketi sonuçları değerlendirildiğinde, Agisoft PhotoScan programı toplamda en yüksek puanı alması ile Autodesk 123D Catch programına göre daha başarılı olduğu belirlenmiştir. Autodesk 123D Catch programı puanlama çizelgesine göre değerlendirildiğinde, arayüz kolaylığı ve kullanım kolaylığı kriterleri bakımından orta derecede avantajlı bir program olduğu görülmektedir. Agisoft PhotoScan programının aldığı puanlara bakıldığında, Beyaz dengesi, pozlama değerleri, parlaklık ve kontrast aralık değeri, fotoğraf çözünürlüğü, ışık ve gölge dengesi, optik bozulma, netlik, ISO hassasiyeti ve diğer programlar ile çalışma uyumu kriterleri açısından düşük derecede avantajlı olduğu ortaya çıkmaktadır. Ayrıca Agisoft PhotoScan programı, oluşturduğu 3B modellerin gerçeğe yakınlık düzeyi kriteri açısından orta derecede, modelleme esnekliği kriteri açısından ise yüksek derecede avantajlı olduğu belirlenmiștir (Tablo 6.).

Tablo 6. Morus nigra 'Pendula' (Sarkık Dut) ağaç türü 3 boyutlu modeli uzman anketi puanlama çizelgesi

\begin{tabular}{|c|c|c|c|}
\hline KRİTERLER & 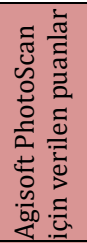 & 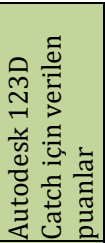 & 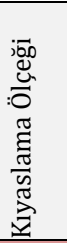 \\
\hline Beyaz dengesi & 93 & 69 & 24 \\
\hline Pozlama değerleri & 93 & 75 & 18 \\
\hline Parlaklık ve kontrast aralık değeri & 87 & 75 & 12 \\
\hline Fotoğraf çözünürlüğü & 99 & 63 & 36 \\
\hline Ișılk ve gölge dengesi & 99 & 93 & 6 \\
\hline Optik bozulma & 87 & 81 & 6 \\
\hline Netlik & 87 & 57 & 30 \\
\hline Alan derinliği & 87 & 87 & 0 \\
\hline ISO hassasiyeti & 87 & 75 & 12 \\
\hline Arayüz kolaylığı & 63 & 135 & 72 \\
\hline Kullanım kolaylığı & 63 & 135 & 72 \\
\hline Modelleme esnekliği & 135 & 45 & 90 \\
\hline $\begin{array}{l}\text { Diğer programlar ile çalışma } \\
\text { uyumu }\end{array}$ & 135 & 105 & 30 \\
\hline $\begin{array}{l}\text { Oluşturduğu 3B modellerin } \\
\text { gerçeğe yakınlık düzeyi }\end{array}$ & 90 & 27 & 63 \\
\hline TOPLAM PUAN & 1302 & 1122 & 180 \\
\hline
\end{tabular}

Chamaecyparis lawsoniana 'Ellwoodii' (Elvudi) ağaç türü için Autodesk 123D Catch ve Agisoft PhotoScan programlarında oluşturulan 3B modellerin kıyaslanabilmesi için yapılan uzman anketi sonuçları değerlendirildiğinde, Agisoft PhotoScan programı toplamda en yüksek puanı alması ile Autodesk 123D Catch programına göre daha başarılı olduğu belirlenmiştir. Autodesk 123D Catch programı puanlama çizelgesine göre değerlendirildiğinde, arayüz kolaylığı ve kullanım kolaylı̆̆ kriterleri bakımından orta derecede avantajlı bir program olduğu görülmektedir. Agisoft PhotoScan programının aldığı puanlara bakıldığında, beyaz dengesi, pozlama değerleri, parlaklık ve kontrast aralık değeri, fotoğraf çözünürlüğü, ışık ve gölge dengesi, optik bozulma, netlik, ıso hassasiyeti, diğer programlar ile çalışma uyumu kriterleri açısından düşük derecede avantajlı olduğu ortaya çıkmaktadır. Ayrıca Agisoft PhotoScan programı, oluşturduğu 3B modellerin gerçeğe yakınlık düzeyi ve modelleme esnekliği kriteri açısından ise yüksek derecede avantajlı olduğu belirlenmiştir (Tablo 7.).

Tablo 7. Chamaecyparis lawsoniana 'Ellwoodii' (Elvudi) ağaç türü 3 boyutlu modeli uzman anketi puanlama çizelgesi 


\begin{tabular}{|c|c|c|c|}
\hline KRİTERLER & 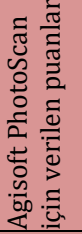 & 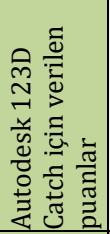 & 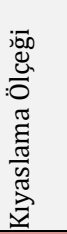 \\
\hline Beyaz dengesi & 93 & 69 & 24 \\
\hline Pozlama değerleri & 99 & 75 & 25 \\
\hline $\begin{array}{l}\text { Parlaklık ve kontrast aralık } \\
\text { değeri }\end{array}$ & 87 & 75 & 12 \\
\hline Fotoğraf çözünürlüğü & 93 & 63 & 30 \\
\hline Ișık ve gölge dengesi & 99 & 93 & 36 \\
\hline Optik bozulma & 87 & 81 & 6 \\
\hline Netlik & 87 & 57 & 30 \\
\hline Alan derinliği & 87 & 87 & 0 \\
\hline ISO hassasiyeti & 87 & 75 & 12 \\
\hline Arayüz kolaylığı & 63 & 135 & 72 \\
\hline Kullanım kolaylığı & 63 & 135 & 72 \\
\hline Modelleme esnekliği & 135 & 45 & 90 \\
\hline $\begin{array}{l}\text { Diğer programlar ile çalışma } \\
\text { uyumu }\end{array}$ & 135 & 105 & 30 \\
\hline $\begin{array}{l}\text { Olușturduğu 3B modellerin } \\
\text { gerçeğe yakınlık düzeyi }\end{array}$ & 111 & 33 & 78 \\
\hline TOPLAM PUAN & 1326 & 1128 & 198 \\
\hline
\end{tabular}

4.2. Kullanılan her iki programının fotoğraf yardımı ile 3B ağaç modellemesi açısından birbirleriyle karşılaștırılması

Autodesk 123D Catch programı, çevrimiçi bir program olması sebebiyle internet bağlantısı olmadan çalışamaması, 3B model oluşturmayı otomatik yapmasından ötürü kullanıcıya modelleme esnasında müdahale etme gibi esneklik sağlayan imkânları sınırlı ölçüde vermesi ve programa en fazla 70 adet fotoğraf karesi eklenebilmesi sonucunda kaliteli ürünler ortaya koyamaması gibi olumsuz özelliklerinden dolayı Agisoft PhotoScan programına göre dezavantajlı olduğu görülmektedir.

Fakat kolay menüsü ve anlaşılabilir arayüzü bakımından da Autodesk 123D Catch programı hem daha pratik hem de kullanımı daha kolay bir program olduğu belirlenmiștir.

Genelde fotoğrafla yapılan çekimlerin arazi deneyimi açısından gözün gerçekte gördüğü üç boyutlu görüntüye en yakın görüntüyü vermektedir (Palmer 1994).

Autodesk 123D Catch programı web sayfasında, insan ve geometrik cansız objeler sorunsuz bir şekilde 3 boyutlu olarak modellenebilmektedir (Autodesk 123D Catch, 2015.). Aynı zamanda bu web sayfasında çok sayıda örnekler sunulmuştur (Şekil 19.).
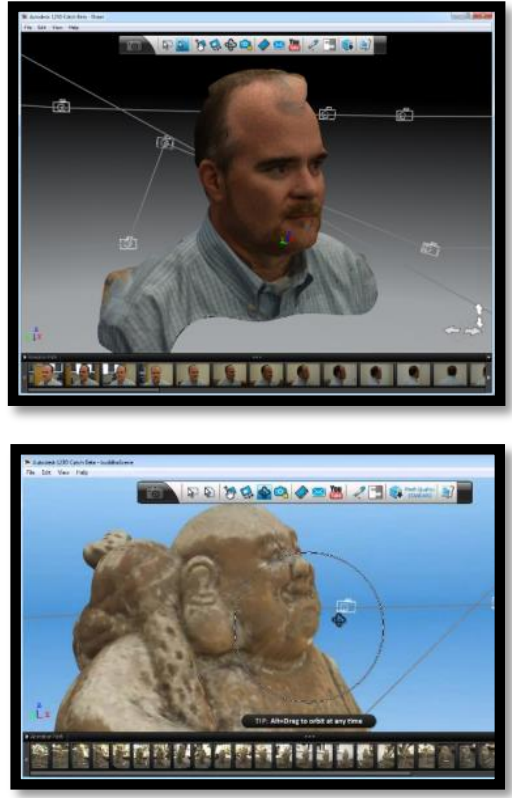

Şekil 19. Autodesk 123D Catch programı ile üretilmiş örnek 3 boyutlu modeller

Ancak bitkisel objelerin 3 boyutlu modellemelerine yönelik hiçbir örnek bulunmamaktadır. Bu çalışma ile elde edilen ağaç 3 boyutlu ağaç modelleri, programın web sayfasında örnek olarak sunulmuş olan insan ve geometrik cansız obje modelleri ile karşılaştırıldığında gerçeğe yakın görsellikte ve istenilen kalitede 3 boyutlu ağaç modelleri elde edilmesi söz konusu olamamıştır.

Çünkü bitkisel canlı objelerin, geometrik objelere kıyasla çok sayıda poligon yüzeylere sahip olması, fotoğraf çekiminin açık havada koşullarında yapılmak zorunda olmasından dolayı fotoğraf çekimi sonucunda istenilen düzeydeki ışık dengesine ulaşılmasının güç olması gibi nedenlerle bu programda istenilen kalitede ve gerçeğe yakın düzeyde $3 \mathrm{~B}$ bitki modelleri üretilmesi mevcut koşullarda mümkün olamamaktadır.

Özçelik (2010)'a göre, üçboyutlu bilgisayar modelleme programlarinda yer alan bitkisel materyaller çoğu zaman modelleme çalışmaları kullanımında yetersiz kalmaktadır. $\mathrm{Bu}$ nedenle yardımcı olarak geliştirilen yama programlar ve çeşitli uygulama teknikleri ile bu açıklık hafifletilmeye çalışılmaktadır. Ama istenilen kalite ve düzeyde olmadığı ifade edilmiştir.

Ayrıca Autodesk 123D Catch programının, Android ve IOS gibi akıllı telefon işletim sistemlerine yönelik uygulamaları bulunmaktadır. Bu bağlamda akıllı telefona sahip olan tasarımcı ve kullanıcıya her ortamda fotoğraf yardımı ile 3B model üretmesi olanağı sağlayarak zaman ve ekipman açısından pratik çözümler kazandırmaktadır. Autodesk'in 123D Catch'i, görüntülerden hızlı bir şekilde oluşturulması ve bunları otomatik olarak modellere işlenmesi ve mobil platformlar için kullanılmasına kolay imkân 
verildiği ifade edilse bile bu çalışmadaki ağaç modellemesinde aynı sonucu vermediği görülmüştür.

Agisoft PhotoScan programında sınırsız fotoğraf eklenebilmesi, 3B modelleme esnasındaki her aşamada kullanıcıyı modellemeye müdahale etme ve düzeltme gibi esnek imkânlar sunabilmesi gibi özellikleri ile daha gerçeğe yakın 3B modeller oluşturmasına olanak sağlamaktadır ve bu özelliğinden dolayı ise Autodesk 123D Catch programına göre daha avantajlı konumdadır. Ancak daha çok fotogrametrik çalışmalarda uygulamalarının bulunduğu program teknik açıdan 3B obje modelleme üzerinde gelişmiş düzeyde değildir. Aynı şekilde bu programla da geometrik düzgün yüzeylere sahip objelerin 3B modellenmesi sonucunda gerçeğe yakın düzeyde sonuçlar alınabilmektedir (Agisoft, 2015).

Bununla ilgili örnekler programın web sayfasında da bulunmaktadır (Şekil 20.). Ancak çok fazla sayıda poligon yüzeylere sahip olan bitkisel (özellikle ağaç ve çalı) objelerin 3B olarak modellenmesi istenilen kalitede ve gerçeğe yakın düzeyde oluşturulması mümkün olamamaktadır.
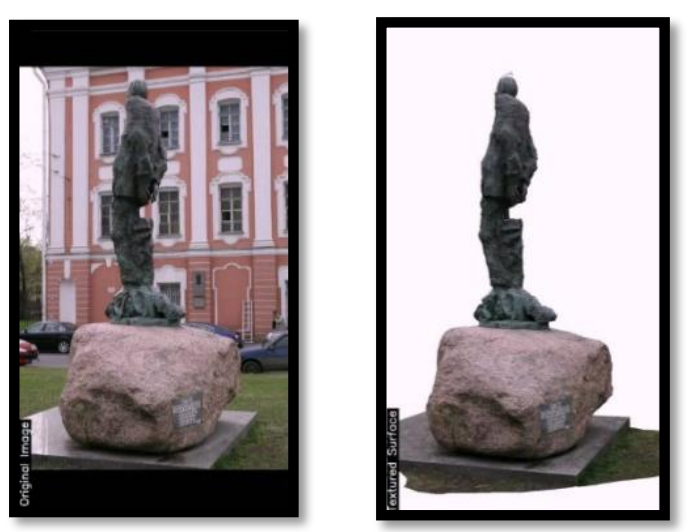

Şekil 20. Agisoft PhotoScan programı ile üretilmiş örnek 3 boyutlu modeller

Agisoft PhotoScan programının, Android ve IOS gibi akıllı telefon işletim sistemlerine yönelik uygulamaları bulunmamaktadır. Bu sebeple program, kullanıcıya pratik çözümler sağlayamamasından ötürü Autodesk 123D Catch programina kiyasla bu konuda dezavantajlı olduğu görülmektedir.

Çalışmada kullanılan programları uzmanların değerlendirmesi sonucunda toplam puanlar üzerinden değerlendirildiğinde; Agisoft PhotoScan programının, Autodesk 123D Catch programına kıyasla fotoğraf yardımı ile 3B ağaç modelleme konusunda daha uygun bir program olduğu ortaya çıkmaktadır.

\section{Sonuç ve Tartışma}

Günümüzde teknolojinin gelişmesi ile birlikte, 3 boyutlu modelleme ve görselleştirme çalışmaları çok yönlü olarak her alanda ortaya çıkmakta ve giderek önem kazanmaktadır. Peyzaj Mimarlığı, Yapı Mimarlığı ve İç Mimarlık gibi tasarımla iç içe olan meslek disiplinlerinin de yaptığı çalışmaları 3B olarak sanal görünümler ile görselleştirmek tasarımcıya ve kullanıcıya büyük avantajlar sağlamaktadır.

Peyzaj Mimarlığı disiplini kapsamında ağaçlar, bitkisel tasarımlarının ana materyalini ve iskeletini oluşturmaktadır. Günümüzde giderek artan ve gelişen 3 boyutlu tasarım çalışmalarında özellikle 3 boyutlu ağaç modelleri de giderek önem kazanmaya başlamıştır. Fakat 3 boyutlu bilgisayar modelleme programlarında hazır olarak yer alan oluşturulan bitkisel materyallerin ölçü, renk ve form bakımından tam olarak gerçeği yansıtamadığı bilinmektedir. $\mathrm{Bu}$ bağlamda, tasarımcı yaptığı bitkisel tasarım projelerini $3 \mathrm{~B}$ olarak modellediğinde, kullandığ ağaçlar ölçü ve form bakımından kendisini yanıltmakta ve projenin uygulanabilirliği açısından sorunları da beraberinde getirmektedir. $\mathrm{Bu}$ sebeple ağaçların ölçü ve form bakımından gerçeği yansıtacak şekilde 3B olarak modellenmesi için doğadaki ağaçların gözlemlenmesi ve edinilen bilgiler doğrultusunda modelleme yapılması ve pratik çözümlerle kullanıma yansıtılması gerekmektedir.

$\mathrm{Bu}$ çalışmada; literatür taraması sonucu fotoğraf yardımı ile 3B ağaç modellemesi konusunda ülkemizde yapılmış herhangi bir bilimsel çalışmaya rastlanılmamıştır. Bu bağlamda ülkemizde bir ilk teşkil etmekte olup bundan sonra ilgililer için fotoğraf yardımı ile bir ağacın nasıl modellenebileceği konusunda bilimsel bir altlık oluşturacaktır. Özellikle proje alan çalışmalarında, mevcut ağaçların ve çalıșma alanının 3 boyutlu rölevesinin yapılmasında, alan sörveyinin oluşturulmasında ve tasarım süreci esnasında; fotoğraf makinesi ile çekilen fotoğraflar kullanılarak hem proje alanının hem de alanda bulunan mevcut bitkisel materyallerin 3 boyutlu modellerin oluşturulması tasarımcı ve kullanıcıya pratik bir çözüm ve kolaylık sağlayacaktır.

$\mathrm{Bu}$ bağlamda Autodesk 123D Catch ve Agisoft PhotoScan adlı programlarda oluşturulan 3B ağaç modelleri açısından değerlendirildiğinde Agisoft PhotoScan programı modelleme esnekliği ve $3 \mathrm{~B}$ modellerin gerçeğe yakınlı düzeyi kriterleri bakımından kullanılan diğer program olan Autodesk 123D Catch programına göre ön plana çıkmaktadır. Ancak iki programda da 3 boyutlu ağaç modeli oluşturulmasında istenilen düzeyde ve gerçeğe daha yakın kalitede görsellik elde edilmesi mümkün olamamıștır. Çünkü bu programların özellikle ağaç modellemesi ile ilgili yeterli teknik özelliğe henüz kavuşturulamadığı görülmektedir. Ayrıca günümüzde 3 boyutlu fotoğraf çeken fotoğraf makineleri bulunmasına rağmen, pahalı ve modelleme programları ile uyumlu olmama gibi olumsuz özelliklerinden dolayı, 3B modelleme konusunda yaygın kullanılması açısından henüz istenilen teknik düzeye sahip olmadığı görülmüştür. Bu nedenle 3 
boyutlu fotoğraf çeken fotoğraf makine modellerin özelliklerinin çeşitlendirilmesi ve fiyat yönünden satın alınabilir düzeye getirilmesi gerekmektedir. Teknolojik olarak sürekli geliștirilen fotoğraf makineleri ile 3 boyutlu modellemeler giderek önem kazanacak ve tasarım çalışmalarında kullanımı yaygınlaşacaktır.

Fotoğraf makineleri ile 3B modelleme yapılabilmesinin geliştirilebilmesi için bu konudaki bilgisayar programları ile fotoğraf makinelerinin yazılımsal açıdan entegrasyonunun sağlanması teknik açıdan büyük yarar sağlayacaktır. Böylelikle gerçeğe yakın ve istenilen kalite düzeyinde $3 \mathrm{~B}$ bitki ve ağaç modelleri üretilebilecektir.

\section{Teşekkür}

$\mathrm{Bu}$ çalışma Süleyman Demirel Üniversitesi Bilimsel Araştırma Projeleri Koordinasyon Birimi tarafından 3931-YL1-14 nolu proje kapsamında desteklenmiştir.

\section{Çıkar Çatışması}

Yazarlar tarafından herhangi bir çıkar çatışması beyan edilmemiştir.

\section{Kaynaklar}

Agisoft, 2015. Agisoft Photoscan Firması Web Sitesi. http://www.agisoft.com (Erişim Tarihi: 10.03.2015)

Akmehmet, V., 2006. Bilgisayar Ortamında Modelleme ve Görselleștirmede Verim Artırımına Yönelik Değerlendirmeler. Yıldız Teknik Üniversitesi, Fen Bilimleri Enstitüsü, Yüksek Lisans Tezi, 183s, İstanbul.

Autodesk 123D Catch, 2015. Autodesk Firması Catch Yazılımı Web Sitesi. http://www.123dapp.com/catch (Erişim Tarihi: 08.03.2015)

Barlas, T., İsen, G., Batmaz, V., 1985. Ben ve Toplum: Sosyal psikoloji I. Teori Yayınları, Ankara.

Dai, M., Li, H., Zhang, X., 2010. Tree Modeling Through Range Image Segmentation and 3D Shape Analysis. Adv. in Neural Network Research \& Application, $67,413-422$.

Graham, M., Davies, A., 2010. 3D Point Cloud Tree Modelling. Intelligence Surveillance and Reconnaissance Division DSTO Defence Science and Technology Organisation, 18p, Edinburgh, Australia.

Kim, J., Jeong, K.I., 2014. Single Image-Based 3D Tree and Growth Models Reconstruction. ETRI Journal, 36(3), 450-459.
Lu, M., 2006. Simulating Cottonwood Tree Growth In Flood Plains Using The Lignum Modeling Method. University of Missouri-Columbia, Faculty of the Graduate School, Ph.D. Thesis, 174p, Columbia.

Özçelik, M., 2010. Peyzaj Mimarlığında Üç Boyutlu Modelleme Tekniğinin Görsel Değerlendirmede Kullanımı. İstanbul Üniversitesi Fen Bilimleri Enstitüsü, Peyzaj Mimarlığı Anabilim Dalı Peyzaj Mimarlığı Programı. Yüksek Lisans Tezi 196s. İstanbul.

Palmer, H., 1994, http://survive.sli.unimelb.edu.au/ rianb/Public/Palmer_et_al.DOC (Erişim Tarihi: 20.03.2016).

Phattaralerphong, J., Sinoquet, H., 2005. A Method for 3D Reconstruction of Tree Crown Volume From Photographs: Assessment with 3D-Digitized Plants. Tree Physiology Journal, 25, 1229-1242.

Sen, S.I., Day, A.M., 2005. Modelling Trees and Their Interaction with the Environment: A Survey. Elsevier Journal Computers \& Graphics, 29, 805817.

Shlyakhter, I., Rozenoer, M., Dorsey, J., Teller, S., 2001. Reconstructing 3D Tree Models from Instrumented Photographs. IEEE Computer Graphics and Application, 21(3), 53-61.

Türker, H.B., 2013. Peyzaj Mimarlığında Kullanılan Ağaçların Bilgisayar Destekli Modellenmesi Üzerine Bir Araștırma. Ege Üniversitesi, Fen Bilimleri Enstitüsü, Yüksek Lisans Tezi, 92s, Bornova-İzmir.

Uzun, Ö.F., 2015. Fotoğraf Yardımı ile 3 Boyutlu Ağaç Modellenmesi. Süleyman Demirel Üniversitesi, Fen Bilimleri Enstitüsü, Yüksek Lisans Tezi, 106s, Isparta. 